\title{
A systematic review on the current conceptualisations of successful psychopathy
}

\author{
Louise Wallace $^{1 *}$, Nadja Heym$^{1}$, Alexander L. Sumich ${ }^{1}$, , \& Dean Fido ${ }^{2}$ \\ 1 University of Derby (UK) \\ 2 Nottingham Trent University (UK)
}
* Correspondence concerning this article should be addressed to Louise Wallace, Nottingham Trent University, 50 Shakespeare Street, Nottingham, NG1 4FQ.
Tel: 0115941 8418. E-mail: louise.wallace@ntu.ac.uk

Word count: 5551

Declaration of Competing Interests

The author(s) declare no potential competing interests with respect to the research, authorship, and/or publication of this article.

\section{Funding}

This work was not support financially. 


\title{
A systematic review on the conceptualisations of successful psychopathy
}

\author{
$\underline{\text { Abstract }}$ \\ The concept of successful psychopathy has been debated for years, however, there is yet no unified \\ approach to its definition and conceptualisation. Such individuals are said to encompass the core \\ traits associated with psychopathy, whilst continuing to function in society, potentially having \\ superior levels of functioning. This review assimilates the existing literature related to successful \\ psychopathy in the general population. An extensive systematic review was performed using four \\ databases, and two key concepts; namely success and psychopathy. After removing duplicates and \\ articles deemed irrelevant, 180 papers were appraised against the review's inclusion and exclusion \\ criteria. The remaining 19 papers underwent quality control by two raters. A narrative synthesis was \\ performed. The key factors associated with the successful psychopathy construct were fearlessness, \\ stress immunity, social potency, normal or superior cognitive performance, professional \\ achievement, stable socioeconomic status, leadership, pride, and aversion to punishment during \\ conflict. Inconsistent findings were considered a result of the variations in psychopathy \\ measurements used, and a lack of an agreed definition of success. Recommendations are provided \\ for the establishment of a unified framework, and the need for a moderated measure of successful \\ psychopathy to allow more systematic research into the notion of successful psychopathy in the \\ general populations.
}

Keywords: psychopathy, success, fearless dominance, adaptation, functioning 


\section{A systematic review on the conceptualisations of successful psychopathy}

\section{Introduction}

Psychopathy is a disorder characterised in part by callousness, a diminished capacity for remorse, superficial charm, impulsivity, and poor behavioural controls (Hare, 1991), and is associated with increased levels of antisocial behaviour and violence (Hare \& Neumann, 2005). These individuals have a propensity for being detained either forensically or clinically and are estimated to make up around $1 \%$ of the general population (Hare, 1999). Dickmans (1990) suggested that people with psychopathy traits frequently demonstrate dysfunctional impulsivity, which describes the tendency to act with less forethought than most individuals of equal ability and could largely be described as leading unsuccessful or below average lives. Of note, the conceptualisations of psychopathy vary within the literature; this ranges from superordinate structures ("psychopathy"), to individual facets; including affective and interpersonal (primary) and lifestyle and antisocial (secondary), to operationalised constructs ("Boldness, Meanness, Disinhibition”).

The antithesis of the prototypical psychopath would be individuals who are able to use such traits advantageously; adapting to society and gaining status and resources whilst exuding minimal effort for maximum output (Babiak \& Hare, 2006). This lends credence to the idea that psychopathic traits can be adaptive and therefore, cannot be denied as potentially successful traits to hold. Indeed, early clinical conceptualisations of psychopathy include adaptive aspects, such as social potency (Cleckley, 1941). However, early measures of psychopathy (Psychopathy Checklist Revised; PCL-R/Self-Report Psychopathy; SRP) did not take into account Cleckley's original positive adjustment traits, such as low anxiety and stress immunity into account, therefore previous research using these measures may have missed key information regarding the psychopathic personality and its application to successful behaviours.

In recent years, there has been a rising interest in the field of so-called successful psychopathy. Such individuals are typically considered to encompass the core psychopathic traits of superficial charm, manipulative interpersonal tactics, callous-unemotional affect, reduced anxiety, and a lack of empathy, guilt, and remorse (Cale \& Lilienfeld, 2002; McCord \& McCord, 1964), whilst continuing to function in society, with some said to have superior functioning that can foster success (Lilienfeld, 2015). Others have claimed the successful psychopath construct is merely a demonstration of those who have been able to fly under the radar and evade capture for their deviant behaviours (Widom, 1977). Indeed, due to the pathological nature of the core traits, many consider the idea of a successful psychopath to be an oxymoron (Kiehl \& Lushing, 2014), raising the critical question as to whether successful psychopathy exists, and if so, how it can be more concretely conceptualised in the literature. All in all, there is currently a lack of clear understanding around 
the conceptualisation of successful psychopathy. Moreover, the ambiguous parameters in defining success make identifying a clear construct complex and uncertain.

Consequently, this review aims to explore the relationship between psychopathy and success more systematically in order to establish a unified framework to our understanding of the construct. It examines how psychopathic traits may manifest in unconventional ways (behaviour and attitudes) and discusses implications for risk and outcome measurement. Finally, it considers the differentiation between the strategic/adaptive use of psychopathic traits and pathological consequences (Murphy \& Stich, 2000).

\subsection{Models of successful psychopathy}

The conceptualisation of successful psychopathy has been limited in its depth and understanding, with several conflicting ideologies surrounding its construct. In order to address this, Lilienfeld (2015) developed three models to explain these manifestations of successful psychopathy; namely, the Differential-severity (DS), Differential-configuration (DC), and Moderated-expression (ME) models. The common assumption for these is that whilst some individuals are being drawn to the maladaptive and pathological nature of their personality, others can be explained as being able to apply their traits to more adaptable behaviours; enabling them to function and appear well-adjusted in society.

The differential-severity model postulates that psychopathy is a unitary construct, whereby those who exhibit psychopathy-related traits differ only in the intensity of their manifestation. This model implies that a successful psychopath encapsulates all of the traits associated with psychopathy, but to a lesser intensity; having lower levels of callousness and manipulative tendencies and displaying fewer instances of reckless impulsive behaviours. This attenuation would allow them to be "successful" in comparison to their higherintensity counterparts, as they would be better equipped to fit into society; thus, passing undetected by any forensic or clinical body. However, this model's main limitation lies in its simplistic view of the construct, whereby success is defined only by the absence of negative outcomes (e.g., incarceration). As the model only accounts for average functioning within society, it fails to address any potential for superior functioning, and so, may not be a complete account of successful psychopathy.

The differential-configuration model posits that the constellation of traits exhibited by those with psychopathic tendencies may differ in successful psychopaths; altering the behavioural outcomes. MullinsSweatt, Glover, Derefinko, Miller, and Widiger (2010) suggested that successful psychopaths share some trait similarities with the prototypical psychopathic individual, however, demonstrate additional traits such as conscientiousness, self-discipline, and low levels of agreeableness, which decrease the likelihood of 
negative outcomes and can assist in societal adaptation. Despite this model demonstrating the potential for successful outcomes, it dismisses the core construct of psychopathy (Cleckley, 1941; Hare, 2003), by suggesting levels of psychopathy can remain high in the absence of affective psychopathic traits (e.g., callousness, reduced empathy). The lack of adherence to the original construct makes this model less desirable as a sole explanation for successful psychopathy.

The foundation of the moderated-expression model emphasises the link between the core psychopathic traits and external moderating factors. The lack of antisocial behaviour and deviant conduct is a result of employing additional external protecting factors such as resilience (Cleckley, 1976), intact executive functioning and higher autonomic responsivity (Ishikawa, 2001), and positive childhood experiences such as good attachment and parental upbringing within a family unit (Frick \& White, 2008; Waller, Gardner, \& Hyde, 2013). Some debate that higher levels of intelligence may also reduce the risk of deviant behaviours exhibited by those with psychopathic traits (Wall, Sellbom, \& Goodwin, 2013). These external variables may allow an individual to channel their psychopathic traits into more socially adept situations and reduce the propensity to engage in antisocial behaviours. The Moderated-expression model appears stronger than the previous two, due to its allowance for interaction between psychopathic traits and external variables, as well as maintaining the core psychopathic traits within its conceptualisation; however, it is not clear whether this model encapsulates the entire construct.

Finally, it can be argued that the most concrete demonstration of successful psychopathy might involve a combination of the proposed models, allowing for decreased trait intensity, collaboration between the core psychopathic traits and moderating aspects, and the existence of protective external factors.

\subsection{Rationale, aims and objectives}

This review presents a systematic investigation into the current research around successful psychopathy to allow for a better understanding of the conceptualisation of the construct as indicated by the wider literature, and the evaluation of the proposed models. As such, current objectives are to (i) examine the present conceptualisation of successful psychopathy in research, (ii) explore the applicability of the successful psychopathy models, and (iii) identify the core traits associated with the successful psychopathy construct. This review differs from previous work conducted on psychopathy, as it is the first to solely focus on successful psychopathy, whilst adhering to a systematic review methodology. 


\section{Method}

\subsection{Search strategy}

The PRISMA guidelines (Moher et al., 2010) were followed to undertake this review. In total, 980 papers were identified as being relevant to the aims of this review. Of these papers, 468 were removed as they were duplicates, 449 were removed as they did not meet the criteria for the review (see section 2.2), and the final papers included were $n=19$. (see Figure 1).
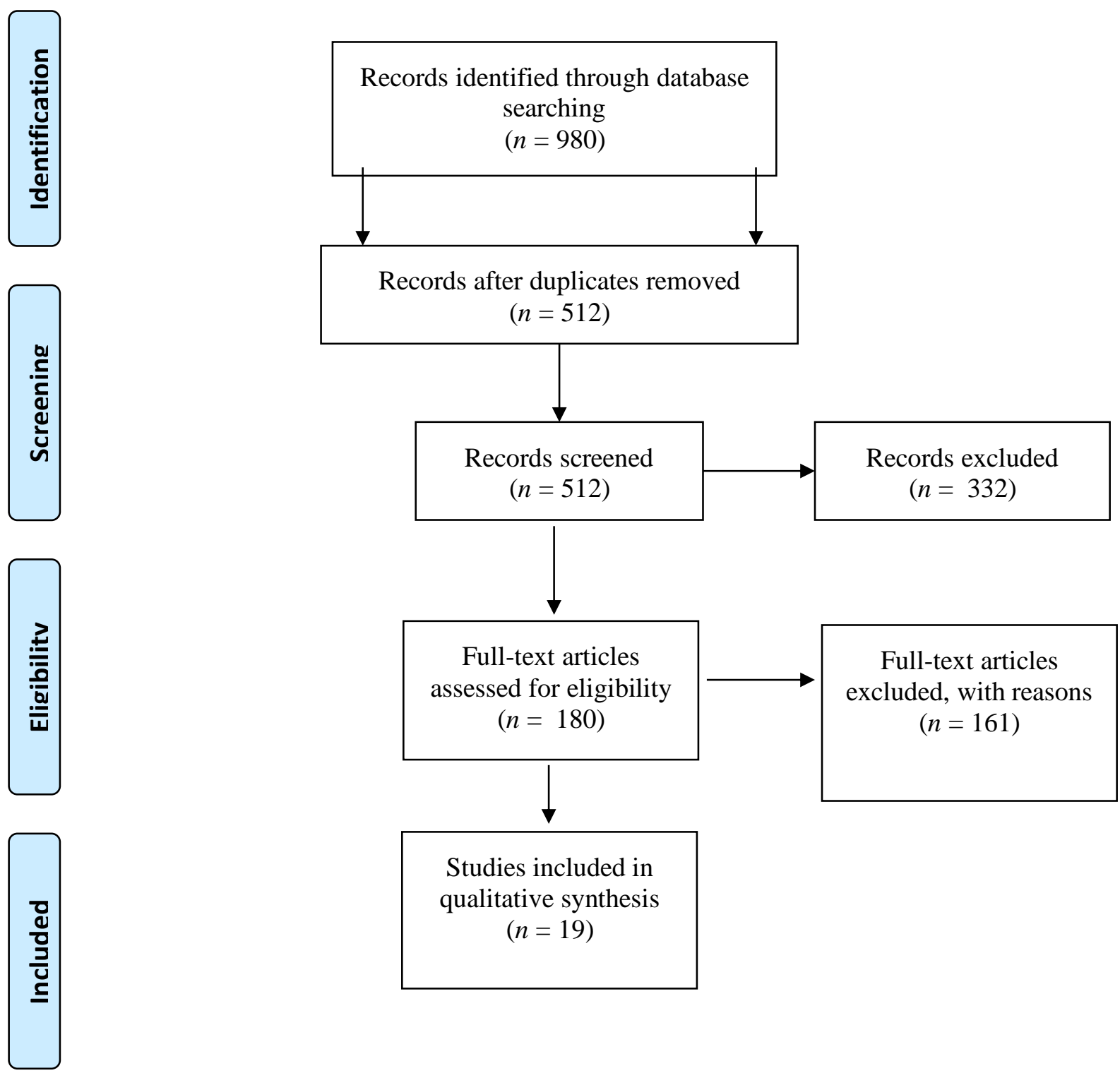

Fig. 1. PRISMA flow diagram (Based on Moher, Liberati, Tetzlaff, Altman, \& The PRISMA Group, 2009). 


\subsection{Inclusion and exclusion criteria}

\subsubsection{Population}

Adults within the general population. Any studies that included participants under the age of 18 were excluded. Studies using only forensic populations (i.e., those incarcerated after committing criminal acts) were excluded.

\subsubsection{Outcome}

"Psychopathy" or "psychopathic traits" as measured by a recognised psychometric measure of psychopathy or measurement, which identifies psychopathic traits within specific populations (e.g., corporate settings). Studies using the PCL- $R$ (Hare; 1985) as a psychometric measure were excluded, as they are most widely used in forensic samples, which does not fit the nature of this review due to the classification of criminal conduct as a defining feature rather than an outcome.

Measures which include psychopathy as part of a broader assessment or a separate construct within a longer measure, such as the dark triad, were excluded to avoid any potential cross-over between the accompanying constructs. Included papers must also demonstrate empirical evidence of psychopathy and individual success (e.g., academic achievement or performance), and show the relationship between psychopathy and at least one outcome behaviour.

\subsubsection{Study characteristics}

Studies selected were predominantly primary research and had cross-sectional designs.

\subsubsection{Report characteristics}

Papers included were all published after 1985 to ensure data is provided after the formalisation of psychopathy assessment; must be available in English; restricted to published studies.

\subsection{Verification of eligibility criteria}

\subsubsection{Information sources}

Electronic Bibliographic Databases Search date: $12^{\text {th }}$ August 2019.

Databases searched: Scopus, PsychInfo, PsychArticles, and ProQuest Central.

\subsubsection{Search terms}

The following search terms were used in all searches: $12^{\text {th }}$ August 2019. 
- Psychopath* (to include 'psychopathy' OR 'psychopathic' OR 'psychopath' OR 'psychopaths'; (in title \& abstract) AND

- 'success*' OR 'adapt*' OR 'function*' OR 'corporate' OR 'leadership' (in title \& abstract)

The exact syntax/strategy used were modified to the requirements of the search location.

\subsubsection{Study selection}

References were compared against the inclusion/exclusion criteria, and those that did not meet the criteria were removed. In addition, a meta-analysis on psychopathy and leadership (Landay, Harms, \& Credé, 2019) was removed from the final stage as it did not meet the study characteristics criteria. However, on closer examination, three papers from the meta-analysis were reviewed in full by both reviewers (Baird, 2002; Costello et al., 2018; Lilienfeld et al., 2014) and were added to the current final selection.

\subsection{Data collection and quality assessment}

To aid in synthesising the data from the selected studies, a data extraction table (see Table 1.) was created. This table included publication characteristics of the papers (e.g., author, year of publication, country of origin), sample characteristics (e.g., age, sex), the measure of psychopathy used, main findings of the studies, limitations, and their quality assessment score.

We used the AXIS tool to assess the quality of all the selected studies within the review (Downes, Brennan, Williams, \& Dean, 2016). The tool consists of a 20-item checklist designed for assessments of crosssectional and observational research. The checklist requires either yes, no, or do not know (for calculations yes $=1$, no/do not know $=0$ ), and a score out of 20 is then generated (note that interpretation is considered subjective, therefore a second rater checked $20 \%$ of the papers included, from which the quality scores were identical following review). For the purpose of the review, scores are divided into three groups; low quality (0-7), medium quality (8-14), and high quality (15-20). The quality score of each included article can be found in Table 1 alongside the additional study data.

\subsubsection{Data synthesis}

A qualitative data synthesis was chosen. The potential for a quantitative data synthesis was excluded due to i) the diverse nature of general population samples, ii) differences in chosen assessment measures, iii) differences in study design, and iv) differences in the data reported. 
Table 1. Summary of findings of successful psychopathy within general population samples

\begin{tabular}{|c|c|c|c|c|c|c|c|c|}
\hline Author (Year) & Article title & Country & $N$ & $\begin{array}{c}\text { Sample } \\
\text { characteristics: } \\
\text { Age: } M(S D), \\
\text { Gender } \\
\text { distribution } \\
\end{array}$ & $\begin{array}{c}\text { Measure of } \\
\text { psychopathy }\end{array}$ & Main findings & Limitations & $\underset{\text { Assessment }}{\text { Quality }}$ \\
\hline Baird (2002) & $\begin{array}{l}\text { The links between } \\
\text { primary and } \\
\text { secondary } \\
\text { psychopathy and } \\
\text { social adaptation }\end{array}$ & USA & 92 & $\begin{array}{l}\text { Males }(\mathrm{N}=42) \\
\text { Females }(\mathrm{N}=50) \\
\mathrm{M}=20(\mathrm{SD}= \\
1.21)\end{array}$ & LSRP & $\begin{array}{l}\text { Primary psychopathy does } \\
\text { not cause deficits in social } \\
\text { functioning - but does not } \\
\text { offer benefits either. } \\
\text { Secondary psychopathy is } \\
\text { related to lack of success in } \\
\text { social functioning. }\end{array}$ & $\begin{array}{l}\text { Lack of } \\
\text { generalisable } \\
\text { results. Measures } \\
\text { used need further } \\
\text { reliability and } \\
\text { validity testing. }\end{array}$ & High \\
\hline Boddy (2014) & $\begin{array}{l}\text { Corporate } \\
\text { psychopaths, } \\
\text { conflict, employee } \\
\text { affective well- } \\
\text { being and } \\
\text { counterproductive } \\
\text { work behaviour }\end{array}$ & U.K & 304 & $\begin{array}{l}\text { Males }(\mathrm{N}=162) \\
\text { Females }(\mathrm{N}=142) \\
(19.4 \% \text { were } 21- \\
30 ; 31.3 \% \text { were } \\
\text { aged } 31-40 ; 20.4 \\
\% \text { aged } 41-50 \text { and } \\
21.1 \% \text { aged } 51-60 \\
\text { with the remaining } \\
7.9 \text { being } 61 \text { and } \\
\text { over }\end{array}$ & PM-MRV & $\begin{array}{l}\text { Compared to normal } \\
\text { managers, dysfunctional } \\
\text { managers and corporate } \\
\text { psychopaths were observed to } \\
\text { display a higher frequency of } \\
\text { purposefully wasting } \\
\text { employer's materials or } \\
\text { supplies, damaging } \\
\text { equipment or property, } \\
\text { working slowly when things } \\
\text { needed to be done, failing to } \\
\text { follow instructions, and } \\
\text { getting into arguments. They } \\
\text { were also observed to be } \\
\text { yelled at more, be the subject } \\
\text { of rudeness, and work in } \\
\text { environment where } \\
\text { unfavourable treatment was } \\
\text { witnessed. Corporate } \\
\text { psychopaths impact conflict, } \\
\text { bullying, and employee } \\
\text { wellbeing, which influences } \\
\text { counterproductive workplace } \\
\text { behaviour. }\end{array}$ & $\begin{array}{l}\text { Medium sized } \\
\text { sample, only } \\
\text { representative of } \\
\text { one population } \\
\text { (United Kingdom) } \\
\text { Self-report bias. } \\
\text { No claims } \\
\text { towards statistical } \\
\text { ability. }\end{array}$ & High \\
\hline
\end{tabular}


Costello,

Unterberger,

Watts, \&

Lilienfeld,

(2018)

pride: fearlessness

and antisocial/

prosocial

behaviour
USA

339

Males $(\mathrm{N}=143)$

Females $(\mathrm{N}=196)$

$\mathrm{M}=38.6(\mathrm{SD}$

$=11.4$ )
PPI-R

Fearless dominance (FD)

positively correlated with

both types of pride. Self

centered impulsivity

positively associated with

hubristic pride and negatively

associated with authentic

pride. Authentic pride

moderated relationship

\section{between FD and}

transformational leadership.

Authentic pride or positive

parenting did no moderate

any relationship between FD

and prosocial/antisocial

behaviour. Hubristic pride

moderated the relationship

between impulsive- antisocial

features and antisocial

behaviour in a protective

manner.

\section{Dalkner et al.}

Psychopathic

personality factor

"Fearless

dominance" is

related to low

self-reported

stress-levels,

fewer psychiatric

symptoms and

more adaptive

stress coping in

psychiatric

disorders

Eisenbarth,

Hart, \&

Do psychopathic

traits predict
Austria

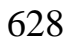

Males $(\mathrm{N}=279)$
Females $(\mathrm{N}=347)$
$\mathrm{M}=52.9(\mathrm{SD}=$

7.7)
PPI-R

(German

version)

U. K

439
Males $(\mathrm{N}=177)$

Females $(\mathrm{N}=262)$
Psychopathic FD traits were negatively associated with

stress and positively

associated with adaptive

coping methods. Stress

immunity and social potency

were positively related to

adaptive stress coping.

Psychopathic traits could be

considered a buffer function

in the development of

depression.

Fearless dominance (FD)

positively associated with

professional success \&
PPI-R

(Short

version)
Self-report,

retrospective

accounts, validity

of pride measure

is questionable.

Reliance on

Mturk sample.
Cross-sectional

research

(longitudinal

needed) self-

report bias,

medications not

monitored, sample

showed below

average

psychopathy

levels.

Relevance of 
material success; Selfcentered impulsivity(SCI) negatively associated. Extraversion predicted material success. SCI and extraversion predicated professional satisfaction. When Big5 added FD no longer associated with material success.

\begin{tabular}{|c|c|c|c|c|}
\hline $\begin{array}{l}\text { Gordon, Baird, } \\
\text { \& End (2004) }\end{array}$ & $\begin{array}{l}\text { Functional } \\
\text { differences among } \\
\text { those high and } \\
\text { low on a trait } \\
\text { measure of } \\
\text { psychopathy }\end{array}$ & USA & 20 & $\begin{array}{l}\text { Males }(\mathrm{N}=20) \\
\mathrm{M}=23.5(\mathrm{SD}= \\
4.1)\end{array}$ \\
\hline $\begin{array}{l}\text { Hassall, } \\
\text { Boduszek, \& } \\
\text { Dhingra } \\
\text { (2015) }\end{array}$ & $\begin{array}{l}\text { Psychopathic } \\
\text { traits of business } \\
\text { and psychology } \\
\text { students and their } \\
\text { relationship to } \\
\text { academic success }\end{array}$ & U. K & 263 & $\begin{array}{l}\text { Males }(\mathrm{N}=104) \\
\text { Females }(\mathrm{N}=158 \\
\mathrm{M}=21.66(\mathrm{SD}= \\
3.61)\end{array}$ \\
\hline $\begin{array}{l}\text { Hill, \& Scott, } \\
\text { (2019) }\end{array}$ & $\begin{array}{l}\text { Climbing the } \\
\text { corporate ladder: } \\
\text { desired leadership } \\
\text { skills and } \\
\text { successful } \\
\text { psychopaths }\end{array}$ & Canada & 25 & N/A \\
\hline $\begin{array}{l}\text { Howe, } \\
\text { Falkenbach, \& } \\
\text { Massey (2014) }\end{array}$ & $\begin{array}{l}\text { The Relationship } \\
\text { among } \\
\text { psychopathy, } \\
\text { emotional }\end{array}$ & USA & 55 & $\begin{array}{l}\text { Males }(\mathrm{N}=39) \\
\text { Females }(\mathrm{N}=16) \\
\mathrm{M}=37.87(\mathrm{SD}= \\
12.40)\end{array}$ \\
\hline
\end{tabular}

No significant behavioural differences were found.

Those high PPI demonstrate a different pattern of neural activity when responding to tasks that require affective processing.

SRP- III

Greater levels of

psychopathic traits in

business students than

psychology students.

Antisocial behaviour and

gender (male) negatively

correlated to grade outcome.

PPD-PRCL 25 adverts were screened for psychopathic traits.

Corporations are seeking out applicants with traits

synonymous with F1

Psychopathy.

PPI-R

intelligence, and
Finance employees showed affective psychopathic traits than other community

samples. Interpersonal affective traits were related to higher levels of interpersonal- psychopathy in regard to material and professional success, self-

report bias, noisy data from online platform.

All male sample, self-report bias,

study design does not allow

examination of specific categories to facial affect.

Results cannot be generalised due to sample population.

Response bias.

Sample size is minimal. Sample

Medium bias.

Small biased sample, selfreport bias, issues with how pro success measured, 
professional

success in finance higher annual income and

higher corporate ranks.

Impulsive- behavioural traits

were negatively related to

emotional intelligence.

Results showed a weak but

significant relationship

between the affective-

interpersonal (Fearless

dominance) traits in

psychopathy and professional

success.

Lantrip,

Towns, Roth,

\& Giancola

(2016)

Psychopathy traits

USA

524

Males $(\mathrm{N}=257)$

Females $(\mathrm{N}=267)$

$\mathrm{M}=23.07(\mathrm{SD}=$

with self-report

rating of executive

functions in the

everyday life of

healthy adults

2.91)

PPI

Antisocial impulsivity (AI)

and fearless dominance (FD)

were associated with worse

inhibitory control. AI was

also associated with worse

ability in monitoring the

effect of one's behaviour on another. FD was associated

with better emotional control

and cognitive flexibility.

Psychopathic traits are

associated with subjective

ratings of executive

functioning $(\mathrm{EF})$ in everyday life.

FFM-

$\begin{array}{llll}\begin{array}{l}\text { Lilienfeld et } \\ \text { al. (2012) }\end{array} & \text { Fearless } & \text { USA } & \text { N/A N/A } \\ & \text { the U.S. } \\ & \text { presidency: } \\ & \text { implications of } \\ & \text { psychopathic } \\ & \text { personality traits } \\ & \text { for successful and } \\ & \text { unsuccessful }\end{array}$

121 expert raters reviewed 42 US presidents and their

$\begin{array}{ll}\text { prototypes } & \text { leadership skills. } \\ \text { of PCL-R } & \text { Fearless dominance (FD) }\end{array}$ associated with better presidential performance (leadership, persuasiveness, and crisis management) as how psychopathy is conceptualised.
Non-clinical sample. Data collected before PPI-R was usable - therefore the study would need replication.

Correlational

research.

Psychopathy trait weren't measured exactly, only estimated from FFM facets. Results cannot be generalised to other positions of well as initiating new projects power 
and being a world figure.

Impulsive anti-sociality was

not associated with rated

presidential performance,

indicating negative job

performance.

\section{Lilienfeld et \\ al. (2014) \\ Correlates of \\ psychopathic \\ personality traits \\ in everyday life}

Međedović

Wertag, \&

Sokić (2018)

Can psychopathic

traits be adaptive?

sex differences in

relations between

psychopathy and

emotional distress

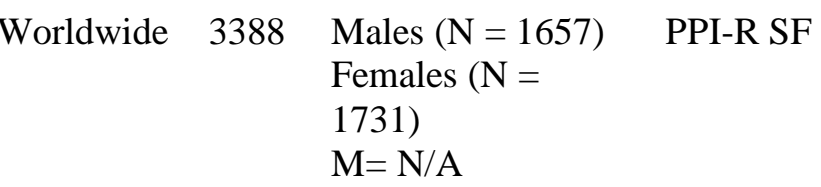

Males $(\mathrm{N}=1657)$

Females $(\mathrm{N}=$

1731)

$\mathrm{M}=\mathrm{N} / \mathrm{A}$

PPI-R SF

Psychopathic traits (Fearless dominance) positively

associated with

leadership/management

positions and high-risk

occupations. Positively

associated with political conservatism, lack of belief in god.

Affective psychopathic traits have adaptive potential and present a protective factor for emotional distress. Lifestyle and antisocial traits represent risk factors for emotional distress. Adaptive traits seem to be more prominent in males than females.

Dictator game (DG) and

Ultimatum game (UG).

Compared with their offers in the DG, individuals with higher scores for primary psychopathy made larger offers in the UG, where low offers could trigger punishment from the recipient. Primary psychopathy did not decrease
Personality and performance can be influenced by luck.

Cross sectional research, selfreport, external validity

limitations.

Self-report bias, no inclusion of environmental factors, student only sample.

Hypothetical

be accurately applied to realworld scenarios. No control for demographic factors

(socioeconomic, intelligence).

population. 
the amounts of offers in either game when the participant considered the recipient to be a friend.

Secondary psychopathy was not associated with

differences in behavioural fairness depending on a potential for punishment or social distance. Gender impacted the game but not psychopathic traits.

\begin{tabular}{|c|c|c|c|c|}
\hline $\begin{array}{l}\text { Pasion, Cruz, } \\
\& \text { Barbosa } \\
\text { (2018) }\end{array}$ & $\begin{array}{l}\text { Dissociable } \\
\text { effects of } \\
\text { psychopathic } \\
\text { traits on executive } \\
\text { functioning: } \\
\text { Insights from the }\end{array}$ & Europe & 10 & $\begin{array}{l}\text { Males }(\mathrm{N}=39) \\
\text { Females }(\mathrm{N}=56) \\
\mathrm{M}=32.0(\mathrm{SD}= \\
11.6)\end{array}$ \\
\hline
\end{tabular}

Positive association between boldness and inhibition.

Meanness accounted for lack of inhibitory control.

Disinhibition explains updating dysfunction.
Self-report bias, no cross

information, used total psychopathy scores, cross sectional research Split-sample, difficulty in extracting nonforensic results

Non-violent psychopathy needs to be investigated. High intelligence could be a moderator of success but not central to causing success.

Psychopathic individual may not accurately report SES. Use of an Mturk sample.
High

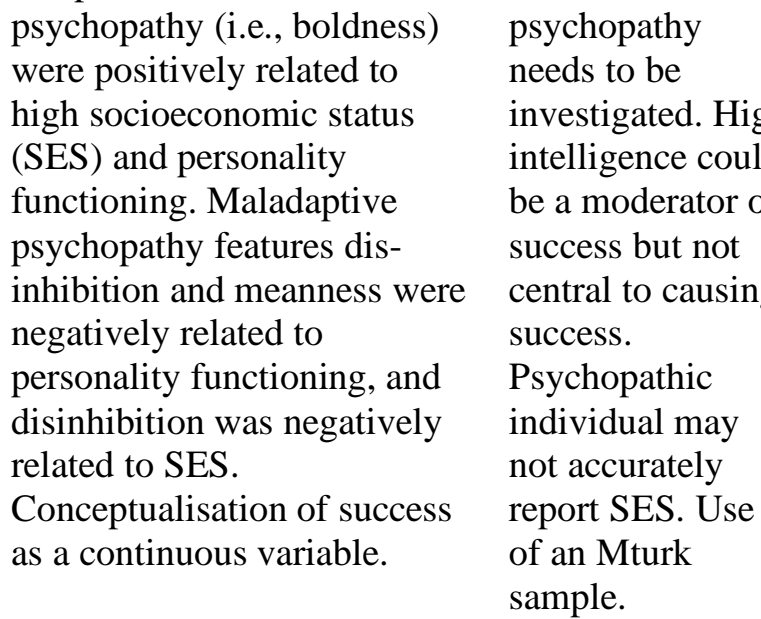

Lilienfeld

psychopathy: An

initial empirical
$\mathrm{M}=39.57(\mathrm{SD}=$ 
corporate

managers and

subsequent

employee job

satisfaction.
$204 \quad$ Males $(\mathrm{N}=105)$

Females $(\mathrm{N}=99)$

PM-MRV,

(age range between 18-69)

LSRP

\section{Australia

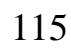 \\ Males $(\mathrm{N}=42)$}

Woods (2013)

between

psychopathy and

the full range

leadership model.

$\begin{array}{ll}\text { Young- } & \text { Are self-report } \\ \text { Lundquist, } & \text { measures of } \\ \text { Boccaccini, \& } & \text { adaptive } \\ \text { Simpler (2012) } & \begin{array}{l}\text { functioning } \\ \text { appropriate for } \\ \text { those high in } \\ \text { psychopathic } \\ \text { traits? }\end{array}\end{array}$

\section{USA}
$107 \quad$ Males $(\mathrm{N}=107)$
$\mathrm{M}=35.98$ (SD
$=12.25$ )

SRP- III
Greater levels of primary

psychopathy (PP) observed

within senior-level managers

compared to the other

corporate designations.

Senior-level managers valued

homogeneity in their

subordinates' personality and

behaviour, identified by high

conformance and

dependability. Role of PP in

sub-ordinate job satisfaction

was unclear.
Only half the

organisational

sample agreed to

take part

indicating a

certain personality

type. Sample not

representative.

Gender bias.

Psychopathy positively correlated with passive leadership, negatively with individual consideration.

Self-report bias, single method data collection.

Fearless dominance (FD) positively correlated with adaptive behaviours. Self centered impulsivity (SCI) and cold heartedness (C) negatively correlated with adaptive behaviours.

Probationers were only accessible sample. Selfreport bias.

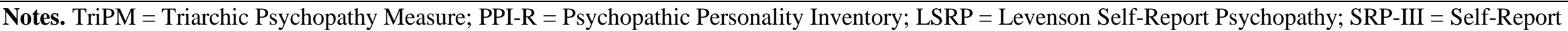

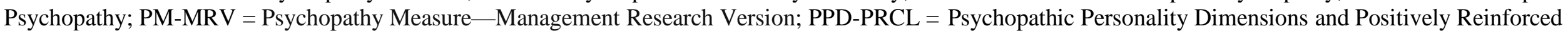
Corporate Labels; FFM = Five Factor Model; PCL- $R=$ Psychopathy Checklist Revised 


\section{Results}

\subsection{Study characteristics}

All 19 studies were published between 2002 and 2019; reflecting the steady growth of interest in the field of successful psychopathy. With the exception of two studies, which had an all-male sample, the majority of the sampled studies reported on both male and female participants $(n=15)$. Additionally, one study provided a content analysis of newspaper advertisements, and a further study examined historical data of presidents of the United States. Most of the studies were conducted in the U.S. $(n=8)$ and Europe $(n=6)$, with others spanning Asia $(n=1)$, Australia $(n=2)$, and one cross-national study.

Seven different measures were used to assess psychopathic traits. The most common measure was the Psychopathic Personality Inventory (PPI; Lilienfeld \& Andrews, 1996), including the revised (PPI- $R$; Lilienfeld \& Windows, 2005) and short-form versions (PPI- $R$-SF; Lilienfeld $\&$ Windows, 2005) $(n=8)$, followed by the Self-Report Psychopathy form version three (SRP- III; (Hare \& Neumann,2012]; Vitacco, Neumann \& Jackson, 2005) ( $n=3)$, the Triarchic Psychopathy Measure (TriPM; Patrick, 2010) ( $n=3)$, and the Levenson SelfReport Psychopathy measure (LSRP; Levenson, Kiehl, \& Fitzpatrick, 1995) ( $n=3)$. The remaining measures capture psychopathic traits in corporate or management environments; Psychopathy Measure-Management Research Version (PM-MRV; Boddy, 2010) $(n=2)$, Wexler's Psychopathic Personality Dimensions and Positively Reinforced Corporate Labels (PPDPRCL; Wexler, 2008) ( $n=1)$. Finally, one study used Fiver-Factor model derived prototypes to assess psychopathic tendencies (FFM; Miller et al., 2001). Some studies used a combination of these measures to assess psychopathy. The full breakdown of each of the included articles can be found in Table 1 .

\subsection{Major findings}

\subsubsection{Fearless dominance}

Five studies primarily examined the relationship between fearless dominance (FD) and outcomes of success. Dalkner et al. (2015) observed that FD (as measured by PPI-R) was associated with reduced stress, and increased social influence, adaptive coping, stress immunity, and fearlessness. This suggests that those with high levels of FD have a blunted stress response or are more effective at coping with the symptoms of stress, thus making them more resilient in daily life, which is a prominent feature of success. 
Eisenbarth et al. (2018) reported positive associations between FD (PPI- $R$-40) and both professional satisfaction and material success, which can be considered direct indicators of success, and negative associations with both depression and anxiety. FD was also shown to correlate with better executive functioning - specifically the ability to move freely from one task to another better emotional control, taking initiative, working memory, planning and organisation, and task monitoring, skills associated with successful outcome behaviours.

Three studies found positive associations of FD with income and leadership skills (Lilienfeld et al., 2014), likelihood of holding everyday leadership or management positions (Lilienfeld et al.,2014), better presidential performance in terms of leadership, persuasiveness, and crisis management, in addition to having the ability to initiate new projects and become a world figure (Lilienfeld et al., 2012).

One paper found FD positively correlated with adaptive behaviours across a composite comprising conceptual, social, practical, and general behaviours (Young-Lundquist, Boccaccini, \& Simpler, 2012). Based on the included studies, FD is an adaptive quality, which lends itself to various means of success, and it is also cited in other themes listed below.

\subsubsection{Stress immunity and vulnerability}

Three studies investigated the relationship between psychopathic traits and emotional distress (e.g., stress). Dalkner et al. (2015) found that the FD domain of psychopathic personality (PPI-R) was negatively associated with stress, and positively associated with adaptive coping and stress immunity. Međedović, Wertag, and Sokić (2018) identified negative associations between the affective-interpersonal dimension of psychopathy (SRPIII) and both stress and anxiety. Moreover, the antisocial dimension was negatively associated with episodes of depression and positively associated with anxiety. In comparison, psychopathic (maladaptive) lifestyle traits (e.g., impulsivity, irresponsibility, and lack of long-term goals) were associated with increased vulnerability for depression. Finally, the adaptive qualities were more prominent in males than females, suggesting sex differences. Eisenbarth et al. (2018) investigated psychopathic traits (PPI- $R$-40) and 
professional success. They found negative associations between FD, depression and anxiety, suggesting resilience to internalising psychopathology.

\subsubsection{Cognitive performance, neural activation, and executive functioning}

One study (Gordon et al., 2004) investigated the functional differences in emotion recognition, as a function of psychopathy (PPI; Lilienfeld \& Andrews, 1996). High and low psychopathy groups did not differ in terms of speed or accuracy. However, high scores in the affective-interpersonal subscale were associated with activation in brain regions implicated in working memory (i.e., the visual cortex and the right dorsolateral prefrontal cortex), whilst low scorers activated regions implicated in emotion (e.g., inferior frontal, medial prefrontal, and amygdala). These findings suggest that distinct cognitive strategies were used to complete the task; working memory may compensate for impaired affective processing. Similarly to how the presence of enhanced cognitive controls enable young adults with callous-unemotional traits to implement effective strategies to achieve their goals (BaskinSommers et al., 2015).

These skills could explain how those scoring high on psychopathic traits compensate for a lack of affective processing when communicating with their peers by using cognitive strategies rather than emotional ones, allowing them to appear emotionally intelligent. Two papers investigated executive functioning $(\mathrm{EF})$ and psychopathic traits. Lantrip et al. (2016) conducted hierarchal regressions and correlations and found FD (PPI; Lilienfeld \& Andrews, 1996) was associated with better emotional control and cognitive flexibility, but worse inhibitory control. This could be due to shared variance with Antisocial Impulsivity (AI) which was associated with poor inhibitory control and ability to monitor the effect of their behaviour on others.

Pasion et al. (2018) used hierarchical linear regression to investigate the relationship between psychopathic traits (TriPM; Patrick, 2010) and executive functioning (EF), assessed via survey and experimental tasks. They found that Boldness was associated with an enhanced ability to inhibit automatic responses, further reinforcing the adaptive potential of Boldness (Patrick et al., 2009). Meanness, on the other hand, was related with high interference scores and a lack of inhibitory control, predicting impulsive behaviour. Disinhibition explained updating dysfunction but did not predict lower inhibitory control. This later finding is 
unusual, warranting further confirmation, but suggests stronger links between the Disinhibition factor and working memory, than inhibitory control.

\subsubsection{Corporate psychopathy and professional success}

One paper investigated psychopathy in corporate managers, where greater levels of psychopathy (PM-MRV; LSRP) were observed in more senior-level managers (Spencer \& Byrne, 2016). Another paper investigated corporate psychopathy (PM-MRV) and workplace behaviours (Boddy, 2014). Corporate psychopaths were seen to exhibit more counterproductive workplace behaviours and workplace conflicts relative to 'normal' (e.g., non-psychopathic or non-dysfunctional) managers. Additionally, they were shown to have a negative effect on employee well-being. Alongside dysfunctional managers, corporate psychopaths were observed to be yelled at more, be the subject of rudeness, and work in environments where unfavourable treatment was witnessed. This suggests that the presence of corporate psychopaths and dysfunctional managers were not conducive of a supportive, achievement-driven work environment. This could imply that these individuals were antagonistic, promoting themselves, whilst causing distress for other employees.

One paper looked at academic achievement in both business and psychology students (Hassall, Boduszek, \& Dhingra, 2015). Psychopathic traits (SRP-III) were reportedly higher in Business students than Psychology students. Of the psychopathic facets, only antisocial behaviour correlated negatively with grade point averages. Contrary to previous research (Babiak et al. 2010) suggesting that psychopathy was related to charisma and presentation as an advantage in business fields, Hassall, Boduszek, \& Dhingra (2015) found no link between any psychopathy factor and (Business) academic success, therefore; despite not measuring charisma and presentation styles within their own study, suggests that charisma and presentation were not associated with academic success.

One paper performed a content analysis for the inclusion of characteristics prominent in psychopathic personalities (PPDPRCL) on 25 executive job advertisements (Hill \& Scott, 2019). The results demonstrated that corporations are seeking applicants with traits synonymous with factor 1 psychopathy, with $96 \%$ of adverts seeking those with the affectiveinterpersonal traits associated with psychopathic personality. 
Two papers investigated professional success and psychopathic traits. Eisenbarth et al. (2018) demonstrated that the FD facet of psychopathic personality was a positive predictor of professional satisfaction and material success. Self-centred impulsivity (but not Coldheartedness) was a negative predictor of professional satisfaction, but was unrelated with material success. The affective-interpersonal facet (i.e., fearless dominance; PPI- $R$ ) was associated with higher annual income and corporate rank, as well as professional success (to a lesser extent; Howe et al., 2014). Thus, suggesting links between FD and reaching a moderate level of professional success.

\subsubsection{Socioeconomic status}

Two studies (Lilienfeld et al.,2014; Persson, \& Lilienfeld, 2019) investigated socioeconomic status as an indicator of success in those with psychopathic traits. Persson et al. (2019) demonstrated that the boldness facet of the TriPM was positively associated with the education, income, and ladder facets of measures of socioeconomic status (SES). Meanness was positively associated with education, whilst disinhibition was negatively associated with all facets of SES. This demonstrates how different facets of psychopathy differentially interact with socioeconomic status. Additionally, the FD facet of the PPI- $R$ was positively associated with higher income (Lilienfeld et al., 2014)

\subsubsection{Pride}

One paper discussed psychopathic traits and pride (Costello et al., 2018). FD has been significantly associated with two subtypes of pride (authentic, hubristic), although it had larger associations with authentic pride, consistent with its adaptive conceptualisation (c.f. Lilienfeld et al., 2012). Authentic pride, however, moderated the relationship between FD and transformational leadership behaviours, such that the interaction accounted for a significant increase in the variance of the outcome. The findings demonstrate that authentic pride may be a partial shaping force in adaptive or successful psychopathy.

\subsubsection{Leadership}

Two studies investigated the relationship between psychopathic personality traits and leadership. Lilienfeld et al. (2014) investigated how psychopathic personality traits correlate with leadership. They demonstrated a positive association between FD (PPI- $R$; Lilienfeld \& Windows, 2005) and leadership. Additionally, cold-heartedness, and self-centred impulsivity 
were also positively correlated with leadership. Westerlaken and Woods (2013) investigated psychopathic traits, as measured by the SRP-III, and leadership. Results demonstrated that those scoring high on the composite psychopathy scale were less likely to demonstrate transformational leadership behaviours (e.g., inspiring, mentoring, and guiding others). Ultimately, those with psychopathic tendencies are more notably identified with passive or avoidant leadership styles, demonstrating behaviours such as evading decision-making and relinquishing responsibilities (Avoilio et al., 1999; Bass, 1999; Sarros \& Santora, 2001). Lilienfeld et al. (2012) performed a content analysis of psychopathic traits (NEO-PI-R; FFMderived prototypes) and presidential performance using 10 dimensions of job performance; overall performance, public persuasiveness, handling of crises, moral authority, economic management, international relations, administrative skills, congressional relations, setting of an agenda, and pursuit of equal justice. One-hundred and twenty-one expert raters completed a questionnaire evaluating the performance and behaviour of previous presidents and their character as it pertains to psychopathic traits. They found that boldness, as derived from FFM data was associated with superior presidential performance, but also with dimensions relevant to FD, such as leadership, communication, persuasiveness, willingness to take risks, and crisis management.

\subsubsection{Punishment sensitivity}

One paper (Osumi \& Ohira, 2017) investigated punishment sensitivity and fairness in psychopathy as measured by the LSRP. The LSRP comprises two factors; i) primary psychopathy, which reflects affective and interpersonal features and ii) secondary psychopathy, which addresses social deviance behaviours. A game scenario instructed individuals to offer money to another player based on the game dynamics. Those with higher composite psychopathy scores made larger offers when a low offer could trigger a punishment from the recipient, indicative of high punishment sensitivity. Primary psychopathy (PP) was associated with lower monetary offers to a stranger, both when there is a possibility of punishment and when there is not. PP was also associated with smaller offers when they were asked to imagine the partner was their friend. These findings suggest that PP is associated with a deficit in their sense of fair behaviours. Secondary psychopathy (SP) was not associated with any differences in fairness regardless of the potential for punishment or relationship to the partner player. 


\subsubsection{Social adaptation}

One paper (Baird, 2002) investigated social adaptation in psychopathy, as measured by the LSRP. This self-report study demonstrated that high primary psychopathy (PP) levels did not hinder social experience, however they did not demonstrate an association to any social benefits either. Secondary psychopathy (SP) was found detrimental to social functioning in terms of peer evaluation. These findings suggest that PP is associated with better social adaptation, at least to normative levels, whereas SP would be disadvantageous in regard to social functioning.

\section{Discussion}

The current study is the first to systematically review existing empirical support for the concept of successful psychopathy. This construct represents individuals who present psychopathy-related personality traits, behaviours, and/or tendencies, yet function normally (or to a superior level) in society, and may use such traits to adapt and facilitate their own success.

\subsection{Synthesis of major findings}

The synthesised evidence suggests that successful psychopathy is best-defined by an amalgamation of two of the three proposed theoretical models of successful psychopathy (Lilienfeld, 2015); Differential-Configuration (DC) and Moderated-Expression (ME). This is indicated by the combination of FD and affective-interpersonal traits, which are more consistently associated with success, but an absence of impulsivity and erratic lifestyle. Moderating factors include stable socioeconomic status, authentic pride, and sex. Whilst Differential-severity (DS) was not measured by any of the included papers, it should not be ruled out. It could be suggested that by increasing psychopathy an individual could become more successful, but extremely high levels could cause this outcome to lower again.

Across the papers, a relatively consistent picture emerged regarding the presence of FD as an adaptive psychopathic trait, suggesting that the construct of successful psychopathy is most closely associated with high levels of FD as a whole. None of the included studies provided in-depth analyses of the sub-facets of FD, for example social potency (a desire to dominate social situations), stress immunity (invulnerability to anxiety, stress, and depression), and fearlessness (a willingness to take risks without fear of reprisal). As such, future studies may 
need to tease apart these components to investigate whether all are involved or just an individual facet.

FD was associated with reduced stress and positive adaptive coping styles (Dalkner et al., 2015), professional satisfaction and material success(Eisenbarth et al., 2018; Howe et al., 2014), higher income (Lilienfeld et al., 2014), authentic pride (Lilienfeld et al., 2012), leadership (Lilienfeld \& Windows, 2005), and adaptive behaviours (Young-Lundquist et al., 2012). Moreover, two papers explored the relationship between EF and psychopathic personality traits (Lantrip, Towns, Roth, \& Giancola, 2016; Pasion, Cruz, \& Barbosa, 2018), which demonstrated that FD was associated with better emotional control and cognitive flexibility. This suggests that affective-interpersonal traits (e.g., superficial charm, lack of empathy, and manipulation; as defined by PPI- $R \&$ TriPM), such as FD, can enhance specific aspects of EF. This is in line with previous research proposing intact or superior EF is key to defining successful psychopathy (Lilienfeld, Watts, \& Smith, 2015). Based on the studies discussed, it is clear that the affective-interpersonal facet of psychopathy has strong adaptability potential; personally, socially, and professionally.

On-the-other-hand, the presence of high antisocial behaviour and related traits caused higher levels of stress and anxiety in individuals with high levels of psychopathic traits (Međedović, Wertag, \& Sokić, 2018; Dalkner et al., 2015). This would support the Differential Configuration model whereby a specific combination of FD and affective-interpersonal traits, with the absence of (or at the very least reduced) antisocial behaviour, underpins the more adaptable outcome behaviours and potential success.

Successful psychopathy is most prominently discussed in terms of professional achievement, however, findings surrounding corporate psychopathy or professional success with psychopathic traits demonstrated some conflicting positions. Firstly, there were accounts of individuals with psychopathic traits being more likely to be in senior management positions (Spencer \& Byrne, 2016), acquiring professional success (Howe et al., 2014), and corporations seeking out those who exhibit psychopathic traits for executive job positions (Hill \& Scott, 2019). However, Boddy (2014) demonstrated that corporate psychopathy was associated with maladaptive workplace behaviours and unfavourable workplace environments. This creates a juxtaposition in terms of individuals with psychopathic traits 
gaining these positions of power and influence in the first place, and their conduct once they achieve their goal thereafter. This lends support to the notion that even if adaptive traits are present allowing for initial success and to fly under the radar (Widom, 1977), maladaptive tendencies and negative consequences prevail and will sooner or later be detected (e.g., Kiehl \& Lushing, 2014). Alternatively, the manipulative nature of psychopaths may allow them to ameliorate or mute maladaptive tendencies for a while to circumvent detection during the recruitment process, by reducing the expression of their maladaptive qualities or emphasise a different configuration of their traits to disguise their darker undertones.

In support of the Moderated-expression model (Lilienfeld et al., 2015), several external moderating factors were prominent within the review. Socioeconomic status was indicated as a protective external factor in terms of enabling an individual with psychopathic traits to become successful. Individuals who scored high on the boldness facet of the TriPM are associated with better educational backgrounds and higher income (Persson et al., 2019). This suggests that ME may also be useful in developing and understanding the trajectory of successful psychopathy, as early life experiences may moderate the outcome behaviours and allow individuals to learn different survival strategies. Another factor highlighted was the presence of healthy pride, conceptualised as the presence of high self-esteem and reward for appropriate behaviours, but also guilt for inappropriate behaviours (Costello, Unterberger, Watts, \& Lilienfeld, 2018). This acts as a moderator between FD and more transformational leadership qualities.

Additionally, even though FD is underpinned by punishment insensitivity or a lack of fear, consideration of consequences during conflict could moderate behaviour to prevent maladaptive outcomes (Osumi \& Ohira, 2017). Thus, higher psychopathic traits indicated an aversion to potential punishment under certain circumstances. Therefore, the key to reducing the disruptive qualities associated with individuals with psychopathic traits may be by introducing these softening or adaptive characteristics, as suggested by the ME model of psychopathy, to alter the outcome behaviours. Potential moderators, such as authentic pride and the desire to avoid detrimental ramifications of their behaviours, alongside FD could be considered fundamental in identifying and attaining success with psychopathic traits.

\subsection{Limitations and future directions}


This systematic review advances our understanding of the delineation and emergence of the concept of successful psychopathy. However, it might be considered limited in the following ways: firstly, the psychometric psychopathy scales used varied across studies, with each measuring a somewhat differing construct. Additionally, studies using the PCL- $R$ were removed from the paper, as the reliance on using forensic populations and the prominence of violent antisocial behaviour was too great and did not fit the theme of the review. However, within psychopathy research it is still considered the gold standard of measurement and the majority of studies within the field use either this measure or forensic samples. Thus, empirical evidence for the construct may be reduced, as an entire subgroup of research is not included, and this also inhibits investigating successful psychopathy as an oxymoron.

Second, the majority of successful psychopathy research is grounded in professional achievement and status, and does not offer a wider view of life success. Therefore, it is difficult to extrapolate from this how these traits would apply to various forms of success, such as general life success. There has been some investigation into psychopathy and mating strategy, but as this review was predicated on the term 'successful psychopathy', this research did not appear in any stages of the review, as success within mating does not necessarily imply a successful psychopath.

It could be suggested that to get a wider view of the construct the use of a life success measure (Parker \& Chusmir, 1992), which looks at not only professional success but success in relationships, personal fulfilment, contribution to society, and security. This could have improved this systematic review as it would have allowed the reviewer to see the application of psychopathic traits in alternative areas and various aspects of life. Future research should focus on unifying the prominent features of successful psychopathy and further developing this construct, discuss the significance of antisocial behaviour to the personality framework, and consider the relevance of existing psychopathy measures when investigating successful psychopathy and their applicability to the construct.

\subsection{Conclusions}

This is the first systematic literature review to analyse the construct of successful psychopathy within general populations. Our results suggest that whilst there are many theoretical conceptualisations of the successful psychopath, there exists limited empirical 
data which can accurately provide a tangible image of this individual. Where other data has been generated to supplement this deficit, this is limited to forensic samples using the PCL- $R$ which is inherently obscure for this kind of research. Most prominently due to the importance placed on antisocial, violent, and criminal behaviour, which would not reflect an inclusive view of the construct as success is only considered in terms of capture delay and a lack of reoffending behaviours. Taken together the findings of this systematic review suggest that successful psychopathy is a complex framework, most simply defined as the lack of antisocial behaviours, the presence of adaptable traits, and positive external factors such as stable socioeconomic status, which provide the best pathway to applying their natures to more successful means. Moving forward with this construct, it would be appropriate to consider a unified framework as described in the introduction to encapsulate all models of successful psychopathy. 


\section{References}

Avolio, B. J., Bass, B. M., \& Jung, D. I. (1999). Re-examining the components of transformational and transactional leadership using the Multifactor Leadership. Journal of Occupational and Organizational Psychology, 72(4), 441-462. https://doi.org/10.1348/096317999166789

Babiak, P., Hare, R. D., \& McLaren, T. (2006). Snakes in suits: When psychopaths go to work. Regan Books New York, NY.

Babiak, P., Neumann, C. S., \& Hare, R. D. (2010). Corporate psychopathy: Talking the walk. Behavioral Sciences \& the Law, 28(2), 174-193.

Baird, S. A. (2002). The links between primary and secondary psychopathy and social adaptation. Colgate University Journal of the Sciences, 34, 61-82.

Baskin-Sommers, A. R., Brazil, I. A., Ryan, J., Kohlenberg, N. J., Neumann, C. S., \& Newman, J. P. (2015). Mapping the association of global executive functioning onto diverse measures of psychopathic traits. Personality Disorders: Theory, Research, and Treatment, 6(4), 336.

Bass, B. M. (1999). Current developments in transformational leadership: Research and applications. The Psychologist-Manager Journal, 3(1), 5.

Boddy, Clive R. (2014). Corporate psychopaths, conflict, employee affective well-being and counterproductive work behaviour. Journal of Business Ethics, 121(1), 107-121.

Boddy, Clive RP. (2010). Corporate psychopaths and organizational type. Journal of Public Affairs, $10(4), 300-312$.

Cale, E. M., \& Lilienfeld, S. O. (2002). Sex differences in psychopathy and antisocial personality disorder: A review and integration. Clinical Psychology Review, 22(8), 1179-1207.

Cleckley, H. (1941). The mask of sanity: An attempt to reinterpret the so-called psychopathic personality. Mosby. St. Louis. 
Cleckley, Hervey. (1976). The mask of sanity: An attempt to clarify some issues about the so-called psychopathic personality. St. Louis (Missouri), Mosby.

Costello, T. H., Unterberger, A., Watts, A. L., \& Lilienfeld, S. O. (2018). Psychopathy and pride: Testing Lykken's hypothesis regarding the implications of fearlessness for prosocial and antisocial behavior. Frontiers in Psychology, 9, 185.

Dalkner, N., Reininghaus, E. Z., Riedrich, K., Rieger, A., Birner, A., Fellendorf, F. T., Bengesser, S. A., Queissner, R., Platzer, M., \& Mayr-Mauhart, M. (2018). Psychopathic personality factor "Fearless dominance" is related to low self-reported stress-levels, fewer psychiatric symptoms, and more adaptive stress coping in psychiatric disorders. Psychiatry Research, 270, 68-77.

Dickman, S. J. (1990). Functional and dysfunctional impulsivity: Personality and cognitive correlates. Journal of Personality and Social Psychology, 58(1), 95.

Downes, M. J., Brennan, M. L., Williams, H. C., \& Dean, R. S. (2016). Development of a critical appraisal tool to assess the quality of cross-sectional studies (AXIS). BMJ Open, 6(12), e011458.

Eisenbarth, H., Hart, C. M., \& Sedikides, C. (2018). Do psychopathic traits predict professional success? Journal of Economic Psychology, 64, 130-139.

Frick, P. J., \& White, S. F. (2008). Research review: The importance of callous-unemotional traits for developmental models of aggressive and antisocial behavior. Journal of Child Psychology and Psychiatry, 49(4), 359-375.

Gordon, H. L., Baird, A. A., \& End, A. (2004). Functional differences among those high and low on a trait measure of psychopathy. Biological Psychiatry, 56(7), 516-521.

Hare, R. D. (1985). Comparison of procedures for the assessment of psychopathy. Journal of Consulting and Clinical Psychology, 53(1), 7. 
Hare, R. D., Hart, S. D., \& Harpur, T. J. (1991). Psychopathy and the DSM-IV criteria for antisocial personality disorder. Journal of Abnormal Psychology, 100(3), 391.

Hare, R. D., \& Neumann, C. S. (2005). Structural models of psychopathy. Current Psychiatry Reports, $7(1), 57-64$.

Hassall, J., Boduszek, D., \& Dhingra, K. (2015). Psychopathic traits of business and psychology students and their relationship to academic success. Personality and Individual Differences, 82, $227-231$.

Hill, D., Scott, H., \& Futter, A. (2019). Climbing the corporate ladder: Desired leadership skills and successful psychopaths. Journal of Financial Crime.

Howe, J., Falkenbach, D., \& Massey, C. (2014). The relationship among psychopathy, emotional intelligence, and professional success in finance. International Journal of Forensic Mental Health, 13(4), 337-347.

Ishikawa, S. S., Raine, A., Lencz, T., Bihrle, S., \& Lacasse, L. (2001). Autonomic stress reactivity and executive functions in successful and unsuccessful criminal psychopaths from the community. Journal of Abnormal Psychology, 110(3), 423.

Kiehl, K., \& Lushing, J. (2014). Psychopathy. Scholarpedia, 9(5), 30835. https://doi.org/10.4249/scholarpedia.30835

Landay, K., Harms, P. D., \& Credé, M. (2019). Shall we serve the dark lords? A meta-analytic review of psychopathy and leadership. Journal of Applied Psychology, 104(1), 183.

Lantrip, C., Towns, S., Roth, R. M., \& Giancola, P. R. (2016). Psychopathy traits are associated with self-report rating of executive functions in the everyday life of healthy adults. Personality and Individual Differences, 101, 127-131. https://doi.org/10.1016/j.paid.2016.05.051

Levenson, M. R., Kiehl, K. A., \& Fitzpatrick, C. M. (1995). Assessing psychopathic attributes in a noninstitutionalized population. Journal of Personality and Social Psychology, 68(1), 151. 
Liberati, A., Altman, D. G., Tetzlaff, J., Mulrow, C., Gøtzsche, P. C., Ioannidis, J. P. A., Clarke, M., Devereaux, P. J., Kleijnen, J., \& Moher, D. (2009). The PRISMA Statement for Reporting Systematic Reviews and Meta-Analyses of Studies That Evaluate Health Care Interventions: Explanation and Elaboration. PLoS Medicine, 6(7), e1000100. https://doi.org/10.1371/journal.pmed.1000100

Lilienfeld, S. O., \& Andrews, B. P. (1996). Development and Preliminary Validation of a Self-Report Measure of Psychopathic Personality Traits in Noncriminal Population. Journal of Personality Assessment, 66(3), 488-524. https://doi.org/10.1207/s15327752jpa6603_3

Lilienfeld, S. O., \& Windows, M. (2005). Manual for the Psychopathy Personality InventoryRevised. Florida: Psychological Assessment Resources.

Lilienfeld, S. O., Latzman, R. D., Watts, A. L., Smith, S. F., \& Dutton, K. (2014). Correlates of psychopathic personality traits in everyday life: Results from a large community survey. Frontiers in Psychology, 5, 740.

Lilienfeld, S. O., Patrick, C. J., Benning, S. D., Berg, J., Sellbom, M., \& Edens, J. F. (2012). The role of fearless dominance in psychopathy: Confusions, controversies, and clarifications. Personality Disorders: Theory, Research, and Treatment, 3(3), 327-340. https://doi.org/10.1037/a0026987

Lilienfeld, S. O., Waldman, I. D., Landfield, K., Watts, A. L., Rubenzer, S., \& Faschingbauer, T. R. (2012). Fearless dominance and the US presidency: Implications of psychopathic personality traits for successful and unsuccessful political leadership. Journal of Personality and Social Psychology, 103(3), 489.

Lilienfeld, S. O., Watts, A. L., \& Smith, S. F. (2015). Successful psychopathy: A scientific status report. Current Directions in Psychological Science, 24(4), 298-303.

McCord, W., \& McCord, J. (1964). The psychopath: An essay on the criminal mind (pp. xi, 223). D. Van Nostrand. 
Miller, J. D., Lyman, D. R., Widiger, T. A., \& Leukefeld, C. (2001). Personality disorders as extreme variants of common personality dimensions: Can the five factor model adequately represent psychopathy? Journal of Personality, 69(2), 253-276.

Mullins-Sweatt, S. N., Glover, N. G., Derefinko, K. J., Miller, J. D., \& Widiger, T. A. (2010). The search for the successful psychopath. Journal of Research in Personality, 44(4), 554-558.

Murphy, D., \& Stich, S. (2000). Darwin in the Madhouse: Evolutionary Psychology and the Classification of Mental Disorders. In P. Carruthers \& A. Chamberlain (Eds.), Evolution and the Human Mind: Modularity, Language and Meta-Cognition (pp. 62-92). Cambridge University Press.

Neumann, C. S., Schmitt, D. S., Carter, R., Embley, I., \& Hare, R. D. (2012). Psychopathic traits in females and males across the globe. Behavioral Sciences \& the Law, 30(5), 557-574.

Osumi, T., \& Ohira, H. (2017). Selective Fair Behavior as a Function of Psychopathic Traits in a Subclinical Population. Frontiers in Psychology, 8. https://doi.org/10.3389/fpsyg.2017.01604

Parker, B., \& Chusmir, L. H. (1992). Development and Validation of a Life-Success Measures Scale. Psychological Reports, 70(2), 627-637. https://doi.org/10.2466/pr0.1992.70.2.627

Pasion, R., Cruz, A. R., \& Barbosa, F. (2018). Dissociable effects of psychopathic traits on executive functioning: insights from the triarchic model. Frontiers in Psychology, 9, 1713.

Patrick, C. J. (2010). Triarchic psychopathy measure (TriPM). PhenX Toolkit Online Assessment Catalog, 813, 814 .

Persson, B. N., \& Lilienfeld, S. O. (2019). Social status as one key indicator of successful psychopathy: An initial empirical investigation. Personality and Individual Differences, 141, 209-217. https://doi.org/10.1016/j.paid.2019.01.020

Sarros, J. C., \& Santora, J. C. (2001). The transformational-transactional leadership model in practice. Leadership \& Organization Development Journal, 22(8), 383-394. https://doi.org/10.1108/01437730110410107 
Spencer, R. J., \& Byrne, M. K. (2016). Relationship between the extent of psychopathic features among corporate managers and subsequent employee job satisfaction. Personality and Individual Differences, 101, 440-445. https://doi.org/10.1016/j.paid.2016.06.044

Vitacco, M. J., Neumann, C. S., \& Jackson, R. L. (2005). Testing a Four-Factor Model of Psychopathy and Its Association With Ethnicity, Gender, Intelligence, and Violence. Journal of Consulting and Clinical Psychology, 73(3), 466-476. https://doi.org/10.1037/0022-006X.73.3.466

Wall, T. D., Sellbom, M., \& Goodwin, B. E. (2013). Examination of Intelligence as a Compensatory Factor in Non-Criminal Psychopathy in a Non-Incarcerated Sample. Journal of Psychopathology and Behavioral Assessment, 35(4), 450-459. https://doi.org/10.1007/s10862013-9358-1

Waller, R., Gardner, F., \& Hyde, L. W. (2013). What are the associations between parenting, callousunemotional traits, and antisocial behavior in youth? A systematic review of evidence. Clinical Psychology Review, 33(4), 593-608. https://doi.org/10.1016/j.cpr.2013.03.001

Westerlaken, K. M., \& Woods, P. R. (2013). The relationship between psychopathy and the Full Range Leadership Model. Personality and Individual Differences, 54(1), 41-46. https://doi.org/10.1016/j.paid.2012.08.026

Wexler, M. N. (2008). Conjectures on systemic psychopathy: Reframing the contemporary corporation. Society and Business Review, 3(3), 224-238. https://doi.org/10.1108/17465680810907305

Widom, C. S. (1977). A methodology for studying noninstitutionalized psychopaths. Journal of Consulting and Clinical Psychology, 45(4), 674-683. https://doi.org/10.1037/0022006X.45.4.674

Young-Lundquist, B. A., Boccaccini, M. T., \& Simpler, A. (2012). Are self-report measures of adaptive functioning appropriate for those high in psychopathic traits? Behavioral Sciences \& The Law, 30(6), 693-709. 
